\title{
Nano-biotechnology breakthrough and food-packing industry- A Review
}

\author{
Helmy EA \\ The Regional Center for Mycology and Biotechnology, Al-Azhar University, Cairo, Egypt- \\ dr_emanhelmy@azhar.edu.eg
}

Helmy EA 2016 - Nano-biotechnology breakthrough and food-packing industry- A Review. Microbial Biosystems 1(1), 50-69

\begin{abstract}
Nanobiotechnology has been renowned as extremely essential scientific and industrialized advancements that have the actual ability to renovate virtually each feature of lifetimes and economy. Chemical and physical methods for the synthesis of nanoparticles are the common approaches, but their use is limited because they are costly and harmful to the environment. In this method, the biological systems such as bacteria, fungi, plants were used to transform the organic metal into metal nanoparticles via the reactive capacity of proteins and metabolites present in these organisms. The biogenic synthesis using biological routes especially fungal pathways is, therefore, the best choice. The use of fungi in the green synthesis of metal nanoparticles has been reported in several promising studies, since fungi contain enzymes and proteins as reducing agents and can be invariably used for the synthesis of metal nanoparticles from their salts. Generally, microbial nanobiotechnology can adapt of packaging stuff, rising barrier characteristics, refining mechanical and heat-resistance, evolving functioning antimicrobial exteriors, and generates nano-biodegradable packaging stuffs. Improving intelligent packaging to elevate the nutritional goods validity timing via nanobiotechnology became the ambition of many corporations. This review will focus on tremendous benefits of nanobiotechnology in nutrition trade concerning Foodstuff Wrapping systems and materials. Such packaging (wrapping) structures would be able to fix minor holes/tears, react to ecological conditions as temperature and/or moisture changes and attentive the client if the food is spoiled. Nanobiotechnology has utilized in inventive improvement of biosensors for recognition of pathogens and chemical pollutants. Elaboration of food analytical approaches for the uncovering of tiny aggregates of a chemical and/or any microbial pollutant during food processing is an extra prospective practice of nanobiotechnology. This will leads to further safety for the food handling approaches.
\end{abstract}

Key words - Biosynthesis - microbial nanobiotechnology - nanoparticles'fungal biosynthesis.

\section{Introduction}

The global economy in the $21^{\text {th }}$ century stems the awareness and thoughts rather than the production and trade applications of physical commodities. Thus, nanotechnology developed in the beginning of this novel era. Nanotechnology, the innovative science arises, has a powerful impression on the world's population than any other previous cognizance and techniques. This is owing to the nanotechnology not only will occupy a major portion of our economy, but also, will form the foundation for revolutionary discoveries and advancements in decades to be coming. Besides, the production of nanotechnology can greatly create wealth; improve health, and almost 
man-made pollution. Hence, nanotechnology has been recognized as the vital scientific and technological developments that have the real potential to transform almost every aspect of lifespans and commerce (Antonio et al. 2014).

In recent years, significant 'nano' research has undertaken to enhance the taste, color, texture, health characteristics and consistency of foodstuffs. Nutrients, perhaps, can afforded hale and hearty by lowering their lipids and salts ingredients with no taste altering, and increasing the bioavailability of certain nutrients (Food Safety Authority of Ireland 2009).

Furthermore, Engineered Nanomaterials (ENMs) and Nano sensors used in food packaging to generate 'Smart Packaging' that maximizes food integrity and indicates food spoilage (FAO/WHO 2009). The properties of materials at the Nano scale can be very different from conventional materials (Oberdörster et al. 2005). Consequently, research has concentrated on understanding these properties and how innovative food products can develop from applications of nanotechnology.

While such applications offer many potential benefits nano technologies are swiftly developing worldwide. The third world-countries are also taking part in the improvement of this technological revolution. Latin America, Brazil, Mexico and Argentina are the leading nations in this area. Consequently, it could notice that nanotechnology seems as a scientific area of rapid growth worldwide; many consider it as the basis for the subsequent industrialized revolution. It is possible that in the nearby future no country would be able to escape from the necessity of researching and developing this technology (Heinlaan et al. 2008).

\section{What is Food Nanotechnology?}

Food nanotechnology is a technique that getting intrusively in the food systems. In the recent years, the standards of nanotechnology have not only employed in the laboratory, but also getting almost all sector of our life especially food production. With the claim of nanotechnology principles, nano-food applications can roughly be distinguished into two forms across the whole diet supply chain, that is, food flavors and food packaging, which have been known as nano inside and nano outside, respectively. The novel properties of nanotechnology at the scale of nuclear and molecular have offered new opportunities for food sector and agriculture sector. Nano-technology in the aspect of food, generally, is the science handled in food chain to the selection, preservation, processing, packaging, distribution and use of safe, nutrition, and wholesome food. For example, the relevance of nanotechnology principles enable to produce more potent food colorings, flavorings, and nutritional additives, antibacterial ingredients for food packaging, and more potent agrochemicals and fertilizers (Chaudhry et al. 2008).

Many nanomaterials used for different food applications on industrial scale. For food packaging and storage containers, Titanium dioxide with a unit size of $100 \mathrm{~nm}$ or less is commonly exhausted as food improver and antimicrobial representative (Long et al. 2006). Similarly, Silver nanoparticles benefitted as antimicrobial agents in food covering, storage containers, chopping boards and refrigerators and health supplement (Wang et al. 2007). Zinc and zinc oxide used as nutritional additives and as antimicrobial mediators in foodstuff wrapping (Brunner et al. 2006).

For that trend of microbial production of nanoparticles used for different applications including food packaging an In vitro mycosynthesis of silver nanoparticles (AgNPs) using Penicillium aurantiogresium, P. roqueforti, Aspergillus niger, Verticillium chlamydosporium var. chlamydosporium, Trichoderma viride and T. longibranchiatum had been investigated by Helmy and Mekawey (2013). The process of silver ion reduction by either extracellular fungal filtrate or intracellular cell-free filtrate was achieved which lead to the development of an easy process for synthesis of silver nanoparticles. Upon exposure of the fungal filtrate to silver nitrate, the latter was reduced to silver nanoparticles as indicated by a color change observed and characterized by UV-visible spectroscopy. The optimum experimental conditions for AgNPs 
synthesis were found to be a temperature of $37^{\circ} \mathrm{C}$ at $\mathrm{pH}$ of 6.0 and a substrate concentration of $2 \mathrm{mM}$ silver nitrate after 24 hours' incubation times in dark and measured spectrophotometrically at $430 \mathrm{~nm}$. Silver nanoparticles produced were characterized by various analytical techniques such as TEM, FT-IR and X-Ray analysis of both EDX and XRD. The obtained results revealed that the size of nanoparticles for all the tested fungi ranged from 8.97 to $16.73 \mathrm{~nm}$ with variable shapes, most of them present in spherical in nature.

Food technology considered as one of the trade divisions where nanotechnology will stand as a vital part in the future. While as, carbon and silicon dioxide were manipulated as food additives and packaging due to their minor particles -often of a few hundred $\mathrm{nm}$ in size-, Platinum and gold nano-wires were handled as biosensors to enhance the food scrutiny (Chen and Mikecz 2005).

It frequently discriminated concerning two styles of nano-food consequences: food flavors (nano inside) and food enfolding (nano outside). Nano-range food flavors could be consumed to enhance groceries validity time, consistency, taste, composition, or even sense pathogens and specify functions as food quality indicators. In the framework of foodstuff wrapping, nanotechnology believed to enhance groceries validity time, sensing any pollutant ingredients, or in general secure the food integrity, by blocking air current crosswise product packaging. A lot of money spent in a global race to apply nanotechnology in foodstuff production, processing and packaging (Qureshi et al. 2012). Application milieu of nanotechnology in food processing is shown below in figure (1).

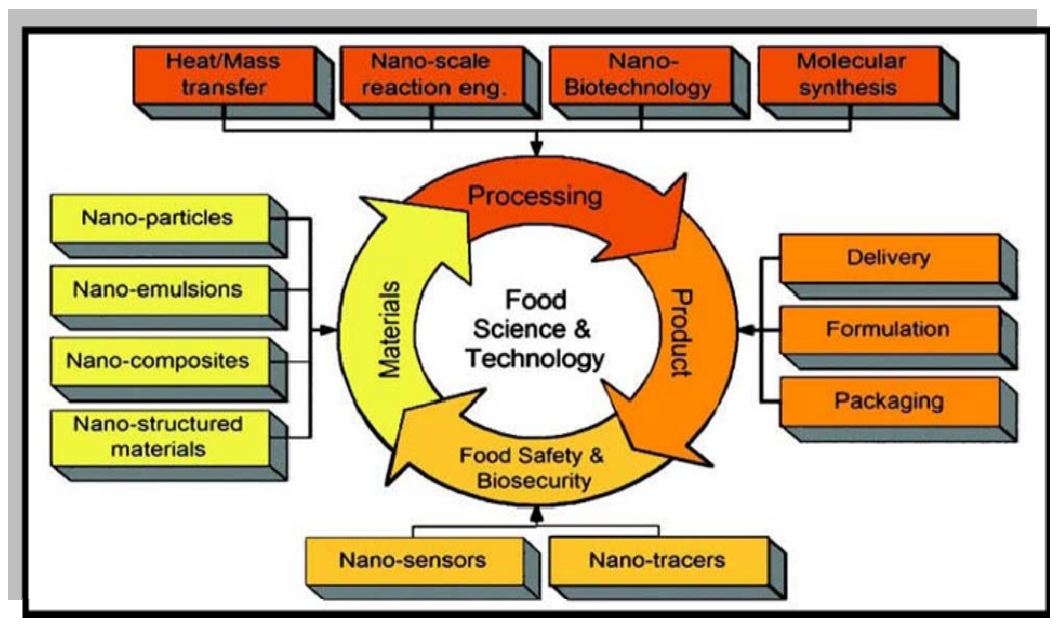

Fig. 1- Application matrix of nanotechnology in food science and technology (Acta Scientiarum Polonorum Technologia Alimentaria 9(4) 2010).

The advantage of applying nanotechnology in nutrition scheme not only improved the food packaging, processing and safety, but also, can enhance the flavor, nutrition of the food, and augment fabrication and cost-effectiveness. Besides, functional foods can be produced in which our daily meals will be supplied with food that carried medicines and supplements. The food goods that produced by concerning nanotechnology are known as nano-food (Berekaa 2015). Estimates of commercially available nano-foods vary widely between 150-600 nanofood-packaging applications (Cientifica 2006; Reynolds 2007).

Qureshi et al. (2012) have defined the term nano-food as: "the food which has been cultivated, produced, processed or packed using nanotechnology techniques or tools, or to which manufactured nanomaterials had been added". Nanotechnology has prospective purposes in all foodstuffs traits including processing, covering and monitoring. As results, thousands of goods 
could be emerges based on nanotechnology in the imminent decades (Zhu 2014).

Despite the tender of nanotechnology in food industriousness is still in the beginning, they are foreseen to develop promptly soon and sponsor the world's economic growth. Thus, the globe's population's gather that nanotechnology can trail to a treasure of pioneering technologies within tremendous fields especially food sector and agriculture (Qureshi et al. 2012).

As one of the primacy capacities in science and technology, Malaysian administration is incredibly fascinated in endorsing nutrition nanotechnology, we must first be understanding the relevance of nanotechnology in diet sectors. Comparable to other prevailing technology fields, foodstuff nanotechnology has conceivable for both value and maltreatment. We must well recognize the capable and capabilities of advanced food nanotechnology before it arrives, and work to prepare for changes it will be bring (Zhu 2014).

Thus, as a consumer, we necessity also well recognize the usage of nanotechnology in nutrition areas and the foods created basis on the principle of nanotechnology. Besides, the successful in foodstuff nanotechnology also plays as contributor to drive the world's economic growth. Thus, the objective of this report is to present a clear picture on the usages of nanotechnology in foodstuff area emphasizing on wrapping and security applications together with the field of antibiotics (Zhu 2014).

\section{Overview of functional nano inside foodstuffs}

Presently, numerous nano-food inventions are in development. Production of functional nutrients like junk foods, soft drinks, ice-cream, chocolate and chips marketed as healthy foods by reducing fat, carbohydrate or calorie content or by increasing protein, fiber or vitamin contents. Nestle and Unilever reported to be developing nano-sized emulsion-based ice cream with a lower fat content but that retains a fatty texture and flavor (Renton 2006).

Many of the industrial corporations as Heinz, Kraft and Nestle are investing in nanotechnology and willing to marketing their goods in the nearest future. For example, they are employing the nanotechnology to change the structure of food, creating "interactive" drinks containing nano-capsules that can change color and flavor (Kraft) and spreads, and ice cream with nanoparticle emulsions (Unilever, Nestle) to improve texture. Others are inventing small nano-capsules that will smuggle nutrients and flavors into the body (Brody 2006). When compared with the nanotechnology applying in electronics, energy and life sciences such as drug delivery, pharmaceuticals and medicine, the implication of nanotechnology in food industries is still relatively recent and mostly theoretical.

Amongst this trend of using microbial biosynthesized nanoparticles-drug complex as drug delivery agent for pharmaceuticals and medicinal drugs for treatment of famous lethal cancer diseases a promising study got made by Elmasry et al. (2016) concerning the formulated quercetin (Q) loaded MNPs mediated by Aspergillus oryazae using $\mathrm{FeSO}_{4}$ as a substrate to prepare MNPs in a single step, co-friendly biological method. The cytotoxicity of the formulated NPs was examined against different human cancer cells. The enhancement of the most sensitive cancer cells in response to radiation therapy (RT) by QMNPs was demonstrated via several cytotoxicity assays including cell survival, intracellular ROS levels, early DNA damage and cell apoptosis in sub G1 phase and cell cycle distribution were measured with MTT assay, Electron Spin Resonance (ESR) Spectroscopy, flow cytometry analysis, respectively to evaluate the biocompatibility of the formulated the nano-structure. The results revealed that $\mathrm{Q}$ was loaded on the surface of the prepared MNPs to obtain QMNPs suggesting that ferric ions are in globular nanoparticles chelated by quercetin. The formulated NPs were amorphous with size ranging from 40 to $60 \mathrm{~nm}$. Biological investigations displayed that QMNPs was concentration dependent and cell specific cytotoxicity with $\mathrm{IC}_{50}$ values of $11 \mathrm{nM} / \mathrm{ml}, 75.4 \mathrm{nM} / \mathrm{ml}$ and $10^{4} \mathrm{nM} / \mathrm{ml}$ for MCF-7, HepG2 and A459 cell lines respectively. QMNPs also, appeared to be a potent enhancer for 
radiation treatment as evidenced by the increased radiosensitivity of MCF-7 cells in comparison with RT alone.

Table 1 Nanomaterials and nanostructures will provide specific function in targeted applications and some examples are listed below

\begin{tabular}{|c|c|c|}
\hline Type of Nanoparticles & Application & Function \\
\hline Metal nanoparticles (Ag, Zn) & $\begin{array}{l}\text { Food additives/supplements } \\
\text { Packaging materials/storage } \\
\text { Food preparation devices } \\
\text { Refrigerators, storage containers } \\
\text { Water purification/soil cleaning }\end{array}$ & $\begin{array}{l}\text { Enhanced gastrointestinal uptake } \\
\text { of metals } \\
\text { Increase barrier properties } \\
\text { Clean surfaces } \\
\text { Antibacterial coatings } \\
\text { Removal/catalysation/oxidation of } \\
\text { contaminants }\end{array}$ \\
\hline Sprays & Refrigerators, storage containers & Antibacterial coatings \\
\hline Complex nanostructures & Nano-sensors in packaging & Detection of food deterioration \\
\hline Hand-held devices & Storage conditions evaluation & Monitoring of contaminants \\
\hline Incorporative active nanoparticles & $\begin{array}{l}\text { Migration out of packaging } \\
\text { materials }\end{array}$ & $\begin{array}{l}\text { Oxygen scavenging, prevention of } \\
\text { pathogens growth }\end{array}$ \\
\hline Filters with nano-pores contaminants & Water purification & Removal of pathogens \\
\hline Nano-sized foods & Food additives/supplements & Claimed enhanced uptake \\
\hline Delivery systems (nano-encapsulates) & Food additives/supplements & $\begin{array}{l}\text { Protecting and (targeted) delivery } \\
\text { of content }\end{array}$ \\
\hline
\end{tabular}

Acta Scientiarum Polonorum Technologia Alimentaria 9(4) 2010.

Although the nanotechnology claims in food area are mostly theoretical, it has been increasingly having a significant effect in the main areas of food industry, from how food grows to how food is being packed (Troncarelli et al. 2013). So, the appliances of nanotechnology in foodstuff industries can be classified into several categories, that is, food processing, food packaging, food preservation and food protection.

The successful submissions of nanotechnology in the food packing and food security areas will be briefly discussed with some examples given in the followings.

Table 2 Applications of nanoparticles in food industry

\begin{tabular}{|c|c|c|}
\hline \multicolumn{3}{|l|}{ Production tool } \\
\hline \multicolumn{2}{|l|}{ Nanosieves } & $\begin{array}{l}\text { Removal of pathogens or } \\
\text { contaminants }\end{array}$ \\
\hline \multicolumn{2}{|l|}{ Nanosensors } & $\begin{array}{l}\text { Detection of microorganisms, food } \\
\text { deterioration }\end{array}$ \\
\hline \multicolumn{3}{|l|}{ Inert nanoparticles } \\
\hline Water purification/soil cleaning & $\mathrm{Al}_{2} \mathrm{O}_{3}, \mathrm{Li}$, nano-Fe & Oxidation of contaminants \\
\hline Food storage & $\mathrm{Ag}$ & Antibacterial \\
\hline Food packaging materials & $\mathrm{Ag}, \mathrm{SiO}_{2}, \mathrm{Mg}, \mathrm{ZnO}$ & Prevention of food deterioration \\
\hline Food supplements & Colloidal metals & Enhanced uptake \\
\hline \multirow{3}{*}{$\begin{array}{l}\text { Nanodelivery systems } \\
\text { Nanocapsules }\end{array}$} & Pesticides & \multirow{3}{*}{$\begin{array}{l}\text { Increased efficacy and water } \\
\text { solubility, } \\
\text { local and controlled release, } \\
\text { increased absorption } \\
\text { bioavailability }\end{array}$} \\
\hline & Bioactive compounds & \\
\hline & Nutrients & \\
\hline
\end{tabular}

\section{Relevance of nanotechnology in food-wrapping}

Food wrapping is the packaging of food which required ensuring delivery of foods to the consumers on the best conditions intended for their use. Food covering has become one of the supreme vital elements to produce successful consumer's products. Nanotechnology enables the 
scientists and allows the designers to alter the structure of food casing constituents on a molecular scale to give the materials desired properties. Thus, nanotechnology has increasingly been employed in food covering and had been commercially applied. Food packaging ingredients that are originated by nanotechnology has become the prime class of modern nanotechnology usages for foodstuff sector (Arora and Padua 2010).

The Relevance of Nanotechnology in Food-Wrapping have led to the elaboration of smart, active and intelligent food packaging that can improve the quality and safety of food to customers by responding to ecological variations. The materials that used for Food-Wrapping are produced from fossil fuels and are particularly none-degradable. The usage of these nondegradable materials in foodstuff has generated a serious global environmental problem; waste problems (Brody 2006).

Before the usage of nano-items in food packets, bio-based ingredients were handled to replace those non-degradable. To explore the novel bio-created casing stuffs, a big effort has made to extend the validity time and enhance food quality and to further design packaging materials to fulfill the targeted food requirements though lowering packing waste. These novel bio-built wrapping stuffs are perhaps eatable and bio-degradable films which made from renewable resources. These degradable bio-based materials believed, could at least, to solve the global environmental problems; the waste problems, to some extent due to their biodegradable nature. Recently, foodstuffs wrapping products occupy most the nanotechnology inventions in food manufacturing sector (Cha and Chinnan 2004)

Scientists predicted that by the end of 2020 the foodstuffs-wrapping sector would dominate all the future nanotechnology diet applications. This is primarily owing to the vast expansion of nanotechnology in this arena, to an advanced reception by customers of the use of this technology in packaging than in food as ingredients. Actuality, there are numerous extra tenders in this theme than in others of food area, jointly with the necessity for more sustainable, lighter and stronger together, active and intelligent packages. These packages would be able to provide safer products with more quality and all at once maintaining the goods in the best possible conditions and with an extended validity time (Gutiérrez et al. 2012).

Today's customers require a lot of packaging in terms of protecting the quality, freshness and food safety and nanotechnology, which uses nano-particles, effective and affordable, and will bring out a proper diet and packaging milk soon (El Amin 2006).

Nanotechnology applications in food packaging materials are considered one of the first commercial applications of nanotechnology in the food sector. About 400-500 on the Nano packaging products are estimated to be in commercial use now, while the expectation of nanotechnology for use in the manufacture of $25 \%$ of all food packaging over the next decade and a large purpose of nanotechnology packaging is to identify longer life by improving the function of food packaging barrier to limit the exchange of gases and moisture and ultraviolet rays of light. For example, it was announced the release of the second additive nano titanium dioxide, a plastic "light stabilizer210", which can reduce UV damage of foods in transparent packaging (El Amin 2007a). Food market requires technologies, which are essential to maintain market leadership in the food industry to produce food products, authentic, comfortable and tasteful new. Lengthen the shelf life and freshness of products as well as improving the quality of the food is the goal.
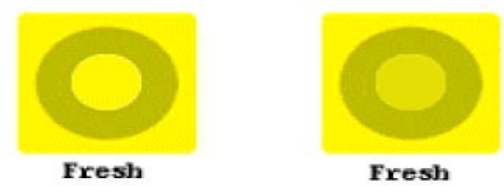

Fig. 2 - Freshness indicators.
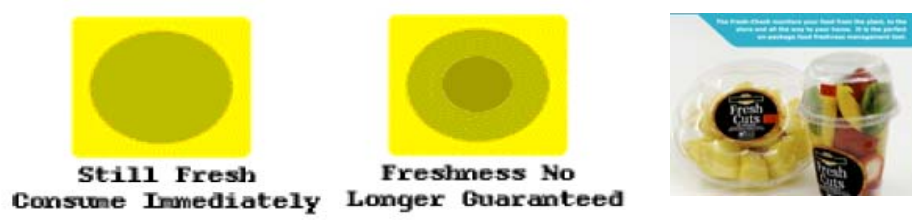
(https://www.google.com.eg/url?sa=i\&rct=j\&q=\&esrc=s\&source=images\&cd=\&cad=rja\&uact=8\&ved=0a hUKEwi2qcuLhtfLAhUFXhoKHYq7BUkQjhwIBQ\&url=http\%3A\%2F\%2Fwww.slideshare.net\%2Fslijko ordjw\%2Fsmart-packaging-for-connected-food-links-compatibility-

mode\&psig=AFQjCNGVXa5PjqMqj1C7sQEq2RaE1qwZ6A\&ust=1458830453381182).

Nanotechnology is a technology that has the potential to revolutionize the food industry. Detect very small amounts of chemical pollutants, viruses or bacteria in food systems is another possible use of nanotechnology (Shefer and Shefer 2003).

It was stated that there are many potential applications of nanotechnology in the food industry. Applications in food packaging are considered very promising because it can improve the safety and quality of food products. This includes packaging active, which can interact with food products and packaging clever (Duncan 2011).

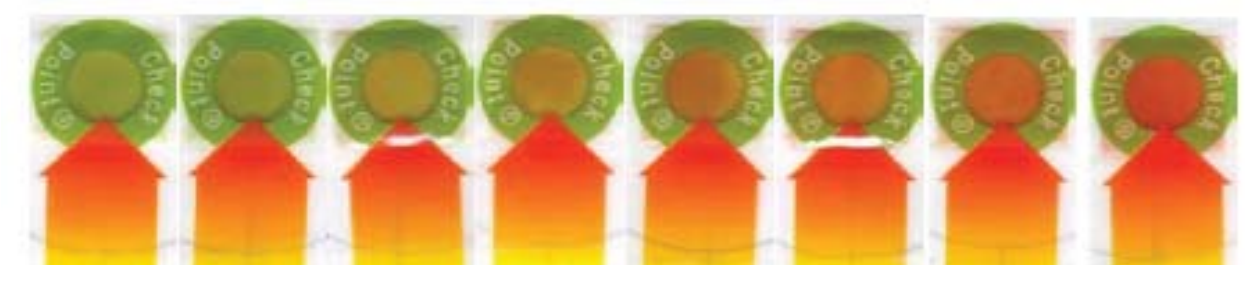

Fig. 3 - Enzyme and pH change results in a color change.

(https://www.google.com.eg/url? sa=i\&rct=j\&q=\&esrc=s\&source=images\&cd=\&cad=rja\&uact=8\&ved=0a hUKEwjZ27mchtfLAhUB0xoKHQQhAToQjhwIBQ\&url=http\%3A\%2F\%2Fwww.slideshare.net\%2Fsuk miyati\%2F00-keynoteg-

robertson\&psig=AFQjCNGVXa5PjqMqj1C7sQEq2RaE1qwZ6A\&ust=1458830453381182).

\section{Active packaging}

Active packaging thought to incorporate components that liberate or absorb substances in the package or in the air in contact to food. Up to now, active packaging has being mainly developed for anti-microbiological applications, nevertheless other promising applications include oxygen caption, ethylene elimination, $\mathrm{CO}_{2}$ absorption/emission, steam resistances, bad odors' protection, liberation of antioxidants, protective additives and additives or flavors. Nanoparticles used to develop a more active packaging and packaging materials are ultrafine metal oxide minerals in the packaging of antimicrobial. The use of silver nanoparticles in packaging active helps to maintain the health conditions in the surface of the food to avoid or limit the growth of microbes. However, its action is not as a preservative even though, it is a biocide based on these characteristics, and the establishment of many food contact materials, which inhibit the growth of microorganisms "(i.e., plastic containers and bags for food storage) (Morones et al. 2005; Suppakul et al. 2003).

To ascertain the prospect of the antimicrobial potential of the fungal biosynthesized AgNPs they were systematically evaluated against fourteen pathogenic bacteria and eight fungal isolates included four isolates of yeast like fungi in a recent study of Helmy and Mekawey (2014). Remarkably, the AgNPs-antimicrobial activity was evident particularly against highly infectious tested isolates like methicillin-resistant Staphylococcus aureus (MRSA), Pseudomonas aeruginosa, Klebsiella pneumoniae, Alcaligenes faecalis, Escherichia coli, as well as several fungal pathogens like Candida albicans, C. tropicalis, Trichoderma reesei, Aspergillus niger and Penicillium marneffei.

\section{Intelligent packaging}

Intelligent or smart food packaging include nano-sensors for sensing signals from germs and biochemical changes, and the release of antimicrobial and antioxidant enzymes, flavors and nutrients to extend shelf life. Nanotechnology can also be applied in the paint or packaging labels and provides information about the track and trace out, as well as within the terms of the 
product through the entire food chain. Some examples of these applications are: undiscovered leak foodstuffs packed under vacuum or inert atmosphere (when the inert atmosphere has been tearing some vehicles consumers change the color temperature rise, which has come into the air in the place which must be inert atmosphere) (Mills and Hazafy 2009).
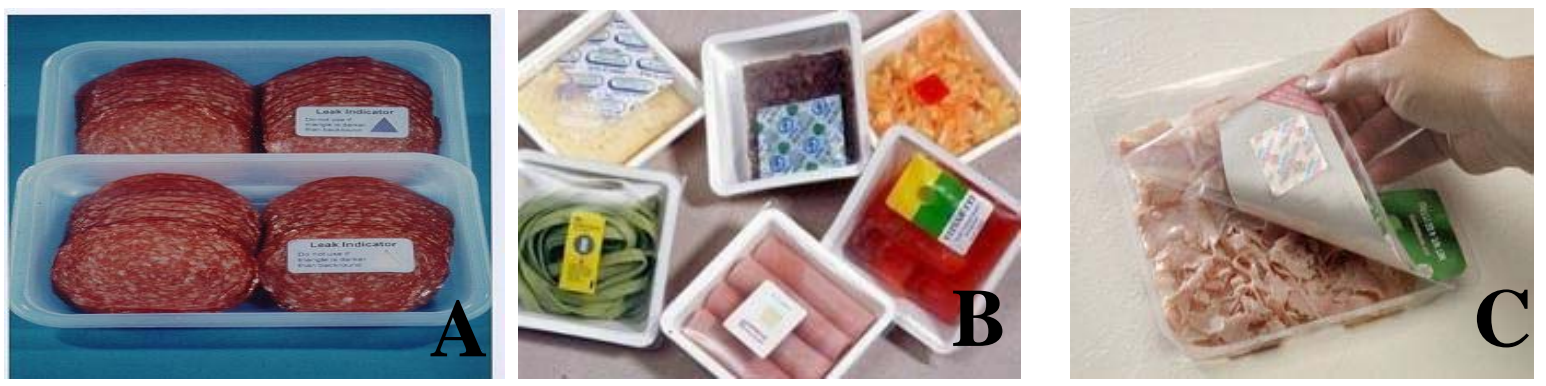

Fig. 4 - (A); Leakage indicators by changes of dye color in presence of air; $\left(\mathrm{TiO}_{2} \mathrm{Nanoparticles}\right.$ are used), (B\&C); Fresh Tags; colour change in response to the release of volatile amines (https://www.google.com.eg/url?sa=i\&rct=j\&q=\&esrc=s\&source=images\&cd=\&cad=rja\&uact=8\&ved=0a hUKEwiZlpykh9fLAhUGPRoKHTvMCYEQjhwIBQ\&url=http\%3A\%2F\%2Fwww.freshpointtti.com $\% 2$ Farticle $\% 2$ Ftime-temperature-integrators-the-current-technology-and-future-developments.aspx\&psig=AFQjCNGVXa5PjqMqj1C7sQEq2RaE1qwZ6A\&ust=1458830453381182).

Changes in temperature (freeze-thaw-refreeze, and monitor the cold chain by silicone with Nano pores) structure, moisture and differences from the product shelf life or food which rose from (the presence of germs is normal). Recently, (Yang et al. 2009) studied sensors based on the coated nanoparticles in a polymer matrix isolated to detect and identify pathogens transmitted by food. These sensors work that produces a certain type of answer all microorganisms.

\section{Nanomaterials to Improve Food-Wrapping characters}

In the following section, some nanotechnology-derived applications of materials in contact with food will mentioned. These applications are presently obtainable in markets while some are at research level. Requests for food contact materials (FCMs) using nanotechnology that Nano boosters to form a nano-polymer composites led minus Polymers performance to new opportunities to improve the characteristics of the poor through the application of the principles of nanotechnology. The method operated to polish the properties of polymer is by adding reinforcing compounds such as silver, titanium, silicon or clay into the polymer to produce nanoparticles-reinforced polymers. Thus, it has been nanoparticles and nano-composite materials that showed very different properties from their own small-sized production counterpart. It has been approved on the nanoparticles and nano-composite materials to compose new properties that can be applied in the development of new packaging with the best of which were produced with small-scale properties (Shefer and Shefer 2003).

Because the goal of nanotechnology in food packaging applications is to improve the safety and quality of food products, remote sensing and diagnosis of chemical damage, pathogens or toxins in food have been emphasized. Hence, these added materials not only for the reinforcement of thermal barrier and mechanical properties, but also, sometimes, to provide some smart properties to packaging such as to certify higher security of foils by modifying the permeation behavior of foils, block the UV light and rising the antimicrobial activity by immobilization bio sensing (Qureshi et al. 2012).

The study of Sundararajan and Ranjitha (2014) have successfully synthesized AgNPs using medicinally important plant leaves of Lagerstroemia speciosa as potential reducing and stabilizing agent. The biosynthesis of AgNPs from L. speciosa appears to be Eco-friendly 
method in nature and for food staff applications. The biosynthesis of silver nanoparticles had several advantages in pharmaceutical applications as well as large scale commercial production, since an effective antimicrobial activity of synthesized AgNPs was demonstrated comparing with Streptomycin and Ketoconazole as control for the tested bacteria and fungi respectively. The results showed that the growth inhibitory zone of $0.6-2.0 \mathrm{~cm}$ for bacterial strains (Staphylococcus aureus, Proteus vulgaris, Pseudomonas aureginosa and Klebsiella sp.) and 0.7 $\mathrm{cm}-1.8 \mathrm{~cm}$ for fungal strains (Aspergillus flavus, Aspergillus niger, Curvularia sp. and Cladosporium sp.). During the past decade, it has increased the use of polymers and materials for food packaging incredibly due to their advantages in the use of traditional materials. Polymers in the global market, which has increased from about 5 million tons in 1950 to nearly 100 million tons now, $42 \%$ in line with the packaging and containers (Silvestre et al. 2011).

As it was previously mentioned, polymers provide packaging with strength, stiffness, oxygen barrier, humidity, protection against certain food compounds attacks and flexibility (Slnchez-Garcya et al. 2010b). The possibility of polymers has been allowed to improve these features in food packaging by adding nanoparticles to develop a wide range of polymers with nanomaterials in composition (Lagaron and Lopez-Rubio 2011).

The use as reinforcement elements of biodegradable cellulosic nano whiskers and nanostructures obtained by electro spinning must highlighted too. The use of Nano composites for food packaging protects not only the food but also increases the shelf life of food products and solve environmental problems and reducing the need to use plastic (Goffin et al. 2011).

The most common particles used for nano reinforcement in food packaging are clay and silicates to produce polymer composites due to their availability, low cost, significant enhancements and relative simple process ability. Nano composites such as Nano clays and Nano films have been used as barrier materials to prevent spoilage and prevent oxygen absorption. Toyota Company was the first companies that produce nano composites as the timing belt covers for their car products. Research on nano-composite applications in the food packaging started since the last 1990s. Nano composite produced by hiring able to delay the deployment of speed to increase the shelf life of food products which, as a composite nano able to perform the role of a physical barrier that are delaying the passage of gases such as oxygen through the package (Gokila and Thiruvengadam 2014).

This nano-composite is the generation that modified from existing materials that can improve the basic properties of materials, food packaging, such as strength, barrier properties, anti-microbial properties, and stability to heat. At the same time, it is not only improving the poor properties of the materials but also offer additional benefits such as low-density, transparency and good flow, surface and better recycling (Gokila and Thiruvengadam 2014). Successful of the packaging materials used for new products and depending on the ability of packaging materials to control the gas composition and the loss of water in the packaging.

For example, the shelf life of vegetables can be extended by about a week and one as nano packs able to control the gas exchange between the internal and external environment of food (Duncan 2011). Instead of using oxygen absorbent material and some chemical companies may begin to produce a movie of nanotechnology transparent plastic to improve the protection of food products (Gouin 2004).

Research and efforts to amend the food packaging materials to the appearance of packaging materials and new polymer composite materials with inorganic nanoparticles, such as nano clay has led (Uricanu et al. 2004). By 2003, and was based on more than $90 \%$ of the nano packaging on the vehicle Nano, which nanomaterials used to improve the function of barrier plastic food wrap, plastic bottles beer, soft drinks and juices.

Nano packaging can also be designed to release antimicrobials, antioxidants and enzymes, flavors and nutrients to extend shelf life (LaCoste et al. 2005). UK research institute believes that it has identified antimicrobial nanoparticles are safe and effective for food 
packaging, a discovery that could revolutionize food packaging in the future happens. The research team reported that nanoparticles of zinc oxide and magnesium oxide shown to be effective in killing microorganisms.
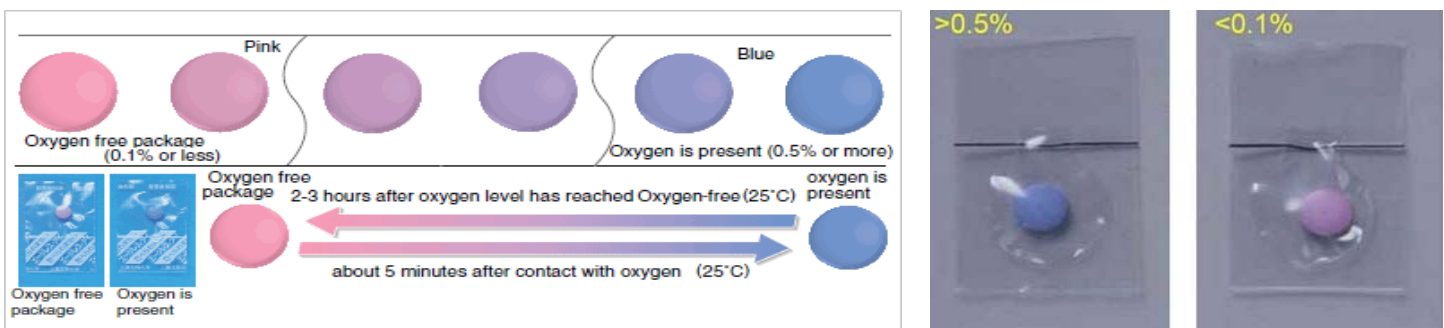

Fig. 5 - $\mathrm{O}_{2}$ indicator tablet; if $\mathrm{O}_{2}$ concentration in atmosphere $\leq 0.1 \% \rightarrow$ indicator is pink. If $\mathrm{O}_{2}$ concentration in atmosphere $\geq 0.5 \% \rightarrow$ indicator is blue, (https://www.google.com.eg/url?sa $=\mathrm{i} \& \mathrm{rct}=\mathrm{j} \& \mathrm{q}=\& \mathrm{esrc}=\mathrm{s} \&$ source $=$ images $\& \mathrm{~cd}=\& \mathrm{cad}=\mathrm{rja} \&$ uact $=8 \& \mathrm{ved}=$ \&url=http\%3A\%2F\%2Fpubs.rsc.org\%2Fen\%2Fcontent\%2Farticlehtml\%2F2014\%2Fcs\%2Fc4cs00039k \&psig=AFQjCNGVXa5PjqMqj1C7sQEq2RaE1qwZ6A\&ust=1458830453381182).

Deng and prove placed composite new Nano, which are nanoparticles functionalized associations, hundreds of micrometers in size and capable of disintegration in the liquid to the nanoparticles, which can be attached to and kill microorganisms and indicate discoveries. This is packaging it will be in the future (Ding and Povey 2005).

\section{Nano-clay}

The incorporation of clay nanoparticles hooked on food was the first Nano composites produced and emerged in markets (Gokila and Thiruvengadam 2014).

Polymer clay nano-composite Nano is a compound which is based on organic polymers and inorganic clay minerals which consist of layers of silicate. Properties of polymers can be improved by adding small amounts of mud at the Nano scale to improve these are included to reduce the gas permeability by increasing the gas barrier properties constitute a barrier to gases and water which force the gas and water to follow winding path; to increase the strength of polymer, to decrease the thermal expansion coefficient while increase the thermal stability; to provide good conductivity properties, and good mechanical properties. At present, there are a huge number of Nano clay polymers available on the market (Duncan 2011).

Some commercial applications are known, such as plastic bottles and beer added to the flexible packaging materials or cardboard in the form of paint (Gokila and Thiruvengadam, 2014). With the introduction of inorganic particles as clay in the biopolymer matrix (Uricanu et al. 2004), numerous advantages are reached.

\section{Nano-film}

Nano-films are films that have been inserted with the nanoparticles, such as clay, in order to improve the physical properties of these films. The nanoparticles play a role to enhance the barrier effect of films such as against oxygen, carbon dioxide, and water vapor while able to maintain the transparency and improve the improvement of hot packaging process. This is due to the effectiveness of the nanoparticles in the film, commercial applications of nano-films and found in food packaging because it is transparent, shiny and perfectly fit to eat. For instance, Nano films have been used as non-stick nano lining mayonnaise and tomato sauce (Ketchup) bottles. As we know that the content of the bottles is so difficult to be removed out, thereby some researches have been done to develop these non-stick nonfood packaging. This non-stick nano packaging is thin films with less than $20 \mathrm{~nm}$ measurements to the inner surface of the food packaging. Even though this kind of Nano films is still not applied commercially, the researcher 
has been started to promote that this product as environmentally friendly solutions as they able to reduce leftover traces condiments in bottles (Gokila and Thiruvengadam 2014). Many of the German research institutes have joined, industry partners and the University of Munich technical forces to develop non-stick nano food packaging for mayonnaise and ketchup bottles (Figure 6).
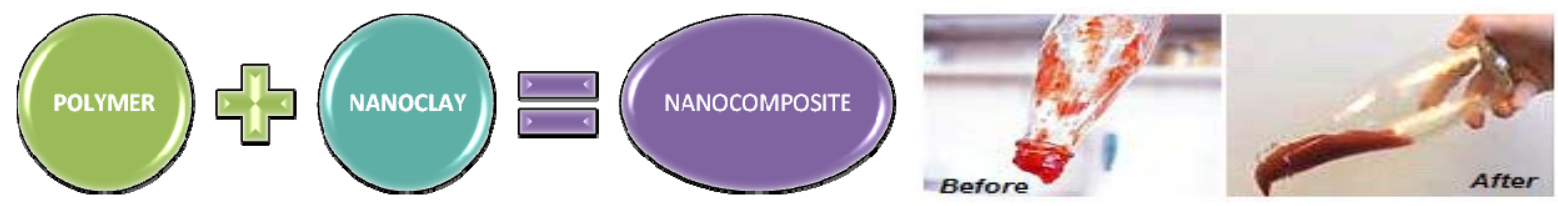

Fig. 6 - Non-Stick nano food packaging for mayonnaise and tomato sauce bottles. (http://www.fastcoexist.com/1679878/mits-freaky-non-stick-coating-keeps-ketchup-flowing).

Similarly, El Amin (2005) reported that the exciting new products of nanotechnology for food packaging are in the way, or as in the case of anti-microbial films, have already entered the market. He added that in the food packaging sector, advanced nanomaterials with the mechanical properties and thermal enhanced to ensure the best foods of foreign mechanical, thermal and chemical or microbiological effects protection. This would grant canned food with an extra level of security and functionality. This would technology is likely to increase the shelf life of foods.

El Amin (2006) It was also stated that the rise in consumer demand to improve the quality and duration of the extended and eco-friendly products shelf life, along with improved regulations in the European Union pushes for more innovation in the food packaging sector. He added that manufacturers of food packaging and responsive to consumer trends and regulatory started, with a focus not only on the development of economic and effective packages for the protection of food products, but also on the aesthetic value of the packages.

Today's customers require a lot of packaging in terms of protecting the quality, freshness and food safety. It is believed that nanotechnology, which uses nanoparticles, effective and affordable, and will bring out the suitable packaging food soon (El Amin 2006).

Scientific and industrial research at the Norwegian Institute of Technology uses nanotechnology to create tiny particles in the film, to improve the transportation of some gases through the plastic film to pump polluted air such as carbon dioxide. It expressed the hope that the concept could be used to prevent harmful gases that shorten the shelf life of foods. Scientists are looking at whether the film can also provide protection barrier and prevent gases such as oxygen and ethylene from deteriorating food (Sintef 2004).

\section{Edible nano composite-based materials}

Nano materials that are suitable vehicle to eat is like edible films and coatings. It has been identified this good movies to eat and paint like a thin, continuous layer of materials suitable for food used in the coating or as a film placed between food ingredients to provide a barrier to mass transfer. The formation and application modes of these two kind of edible Nano composite-based materials on the foods are basically different. When compare the application mode of these two kinds of edible Nano composite-based materials, the edible films are free standing structures which formed first and then applied to foods later, whereas, the application of suitable paint to eat and formed directly on the food. When comparing the formation modes, edible films are formed by casting or by traditional plastic processing techniques, while, food coating is formed by adding a solution to form a liquid film or by molten on food products and vehicles as an integral part of the food (Gokila and Thiruvengadam 2014).

Another trend in the application of nanotechnology packaging and packaging Nano biodegradable is the use of nanomaterials to enhance bioplastic (plant-based) plastic may enable 
bioplastic for use instead of plastic based on fossil fuels for food packaging and tote bags (see Table 3) (El Amin 2007b).

Most packaging materials are not biodegradable, biodegradable current movies of the poor barrier, and mechanical properties, so you need to significantly improve these properties before these films can replace traditional plastic and aid for waste management problem all over the world (Sorrentino et al. 2007).

\section{Nano-coating}

The development of nano-films also leads to the development of nano-coatings good to eat. Paint is a mix partially polymerized to be applied, as is the case in the paper wrapped food that could be made impermeable to water or fat. In tin cans as they could against corrosion. Nano particulate coating is the coating added with nanocrystalline powders which able to improve strength and hardness. Nano coating is different from Nano films as Nano films are made of polymerized materials (Gokila and Thiruvengadam, 2014).

Table 3 Nano- composite biodegradable plastics development and their purposes in food technology

\begin{tabular}{ccc}
\hline Institute or Company & Nano-materials & Purpose \\
\hline $\begin{array}{c}\text { Technical university of Denmark and } \\
\text { others }\end{array}$ & $\begin{array}{c}\text { Nanocomposite biopolymers } \\
\text { using nano clay and other } \\
\text { minerals }\end{array}$ & $\begin{array}{c}\text { Nanoclay and other minerals to } \\
\text { strengthen bioplastics }\end{array}$ \\
\hline Rohm and Haas, USA & $\begin{array}{c}\text { Nanocomposite biopolymers } \\
\text { using paraloid BPM-500 }\end{array}$ & $\begin{array}{c}\text { To strengthen PLA, a biodegradable } \\
\text { plastic resin made from corn, while } \\
\text { maintaining the plastics transparency }\end{array}$ \\
\hline Plantic Technologies, Australia & $\begin{array}{c}\text { Nanocomposite biopolymers, } \\
\text { filler unspecified }\end{array}$ & $\begin{array}{c}\text { Supplied to 80\%of Australian chocolate } \\
\text { tray market Cadbury Australia }\end{array}$ \\
\hline $\begin{array}{c}\text { Australia's Commonwealth Scientific } \\
\text { and industrial Research Organization }\end{array}$ & $\begin{array}{c}\text { Nanocomposite biopolymers, } \\
\text { filler unspecified }\end{array}$ & $\begin{array}{c}\text { Combustible compostable, renewable } \\
\text { and carbon dioxide neutral }\end{array}$ \\
\hline $\begin{array}{c}\text { Sustain pack: 35 research institutes, } \\
\text { Universities and corporate partners } \\
\text { from 13 European countries }\end{array}$ & $\begin{array}{c}\text { Nanocomposite biopolymers } \\
\text { using nano clay }\end{array}$ & $\begin{array}{c}\text { To strengthen fiber based, biodegradable } \\
\text { packaging and to make the packaging } \\
\text { water repellent }\end{array}$ \\
\hline American Journal of Food Agriculture Nutrition and Development (AJFAND), Volume 10, No 6, June, 2010.
\end{tabular}

Edible Nano coating is going to be developed for some of our dairy products such as bakery products, fresh fruits and vegetables. It predicted the food nano coating to be applied commercially because it is transparent and perfectly valid to eat, and can extend the shelf life of food by food protection from damage, prevent exposure to moisture and oxygen, while able to improve the appearance of foods. Lately, nanotechnology has enabled the development of nanoscale thin coating of good to eat, such as five nanometers wide, which are invisible to the human eye. Edible coatings currently used and movies on a wide variety of foods, including fruits and vegetables, meat, chocolate, cheese, confectionery and bakery products, and fried potatoes. Waxy coating is used on a large scale for some foods such as apples and cheese (Qureshi et al. 2012)

It can provide a barrier to moisture and gas exchange and serve to present the colors and flavors, antioxidants, enzymes and anti-browning agents can also increase the shelf life of processed foods, even after opening the package (Renton 2006). American company Sono-Tec Corporation announced in early 2007 it put food on the antibacterial nano-coating, which can be applied directly to bakery goods (El Amin 2007b). Titanium dioxide nanoparticles based, oxygen-sensing inks used as Tamper proofing (Valdiglesias et al. 2013). 


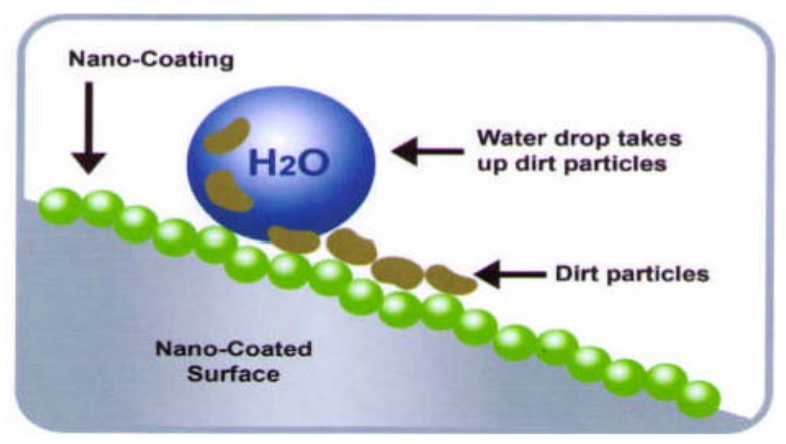

Fig. 7 - Waxy coatings on food products.

(https://www.google.com.eg/imgres?imgurl=http\%3A\%2F\%2Fwww.nanosafeguard.com\%2Fimages\%2Fas dfasdf.jpg\&imgrefurl=http $\% 3 \mathrm{~A} \% 2 \mathrm{~F} \% 2 \mathrm{Fwww}$.nanosafeguard.com\%2Fnano_home\&docid=dPhukVoJsy_y TM\&tbnid=HftI_h6Me7gxMM\%3A\&w=1000\&h=600\&ei=x67yVtWXKIL_aM6il7gD).

Industrial Nanotechnologies (OTC: INTK), a company that specializes in nanotechnology innovation and product development, recently announced the successful implementation of the company, s8217, sNansulate protective coating to provide thermal insulation and corrosion protection of dairy processing equipment. The company said it is the system received a repeat for Nansulate PT dairy plant located in Crowell, Texas, and Nansulate PT used for tanks processing dairy pipes coat to protect against corrosion and insulation against heat loss, and increase the efficiency of the manufacturing process by reducing both energy and related expenses corrosion (Shefer and Shefer 2003).

US dairy industry's annual production is increasing at a rate of about $2.8 \%$ per year, with current expectations for milk production in near future to 183 billion pounds. Because of this huge production and annual increases, energy conservation and the protection of equipment size become important issues for the industry (Nachay 2007).

Colloidal starch coating filled with anti-microbial material can be protected from the food by killing micro-organisms if grown on canned food because it penetrates the starch release of the antimicrobial agent to work with them (Yu and Huang 2010).

\section{Nanosilver}

Another method which is used in food preservation is the use of silver nanoparticles in food packaging. An explosive active and aseptic food container based on silver ions is particularly promising because the ionic form and functionality silver agent powerful antibacterial. The level of nano-silver particles produced by the application of nanotechnology, which can increase the effectiveness of the silver particles measure as nano-sized silver particles have a larger surface area than larger particles of silver. Use of packaging or films that contain anti-bacterial agents that can improve food safety because it can slow the migration of the microbial agent of the carrier structure of the film to the food surface coating (Gokila and Thiruvengadam 2014). Hence Nano silver is more chemically reactive and more readily ionized, thus, able to guarantee high antimicrobial activity.

The researchers suggested that the packaging of food items containing silver nanoparticles is essential to save the food they can extend the shelf life of food by maintaining the growth of contaminants and biofilms after treatment in the form of food contact surfaces. The integration of silver nanoparticles in food packaging would ensure food safety, extend the food's shelf life, and improve foods quality; while the reform requirements of consumers. Silver nanoparticles cannot currently add directly to food, as little about the harmful effects on human health and the impact on the ecosystem is known. However, the programmed research examines how silver nanoparticles can act as antimicrobial in foods, with the goal of developing food- 
related applications such as microbe-resistant fabrics or non-befouling surfaces. This may lead to new approaches for killing food-borne pathogens and enhancing the food safety. He added that the nanoparticles could provide us with a mixture of multiple antimicrobial ingredients that would be physically compatible with other compounds to kill microorganisms and improve food safety (Launois 2008).

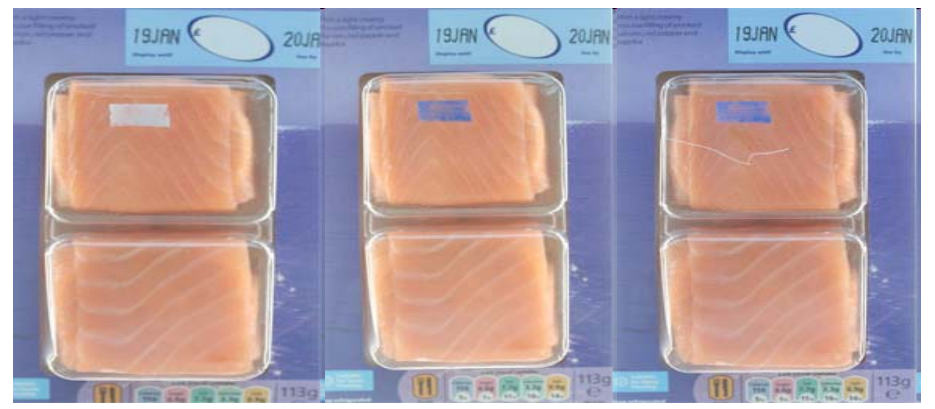

Fig. 8 - Left: before UV activation, middle: after UV activationm and right: on on opening the packages.

(https://www.google.conteglimgres?imgurl—http\%3A\%2F\%2Fimage.slidesharecdn.com\%2Fint elligentpackaging-141105070841-conversion-gate $01 \% 2 \mathrm{~F} 95 \% 2$ Fintelligent-packaging-

24638.jpg\%3Fcb\%3D1415172630\&imgrefurl=http\%3A\%2F\%2Fwww.slideshare.net\%2Fnithyac12\%2F intelligentpackaging\&docid=fElizXDAJy4d1 kM\&tbnidLmE.IpaIaVbvRZAM3A\&w=638\&h=479\&eix 1 0VujI, Joa aOICUmagH).

\section{Silica dioxide and titanium dioxide}

Allowed the traditional huge forms of silica and titanium dioxide food additives are $\left(\mathrm{SiO}_{2}, \mathrm{E} 551\right.$, and $\left.\mathrm{TIO}_{2}, \mathrm{E} 171\right)$. Nano silica is known to be used in food contact surfaces, food packaging, in dried soups as they are free-flowing and in the clearing of beer and wine EFSA European Food Safety Authority (2009). Second Nano Titanium is used in several products including paints, coatings and food oxide. Nano selenium is used as an additive in tea output. And it is currently using functionalized nanoparticles that contain certain functions of the surface and added mainly in food packaging applications (e.g. organically-modified Nano clays), to connect with a polymer to provide mechanical strength or barrier against the movement of gases and volatile components (such as flavors) or moisture.

Integration of nano-clay to ethylene vinyl alcohol copolymer in the biopolymer polylactic acid found to improve the oxygen barrier properties, which may help prolong the life of food products (Lagarón et al. 2005). Other examples that can be cited are the formation of Nano Titanium, which is used to increase the mechanical strength and to aid in processing and titanium dioxide for protection from ultraviolet radiation, in transparent plastic material.

Regarding the microbial biomanufacturing of nanoparticles using radiation an promising research got made by Helmy (2015) as Radiolytic nanoparticles manufacturing granted an economical and environmentally-safely attempts to make metallic nanoparticles in significant with slim dimension dispersity. Aqueous supernatant of Aspergillus oryzae was operated as a securely tool for the establishment of long-standing silver nanoparticles (AgNPs) by way of gamma irradiation at doses from 1 to $30 \mathrm{kGy}$. The volume and the amount of the produced silver nanoparticles (AgNPs) was gamma dose-dependent as it could be altered by managing the radiation dose. The AgNPs outcomes were verified using UV-Visible spectrophotometry, dynamic light scattering (DLS), Fourier Transform infra red (FT-IR) spectrophotometry, X-ray diffraction (XRD), Energy Dispersive $\mathrm{X}$ - ray (EDX) and transmission electron microscope (TEM) analysis which displayed the ultra-morphology of globular AgNPs with 10-17 nm in diameter. The synthesized AgNPs revealed antimicrobial activity against both Gram positive and Gram negative bacteria, as well as some pathogenic filamentous fungi and yeasts as evaluated by 
well diffusion assay technique. In the present study, a nanofactory system to synthesis rapid, ecofriendly and narrow size range of AgNPs was introduced to be used safely in several food applications including storage and packaging. Among these applications, zinc oxide nano and are expected to be affordable and safer solutions for food packaging magnesium soon (Li et al. 2010; Lepot et al. 2011). In addition, carbon nanotubes (Slnchez-Garcya et al. 2010a) or nanoparticles of $\mathrm{SiO}_{2}$ have used for improving mechanical and barrier properties of several polymeric matrices (Vladimiriov et al. 2006). Another trend in this regard is the chemical version nanotechnology packaging. This technology enables food packaging to interact with food. Exchange can be addressed in both directions. Packaging can be called nano-scale antimicrobials, antioxidants, and flavors and fragrances or nutrients in the food or beverage to extend its shelf life or to improve its taste or smell (LaCoste et al. 2005).

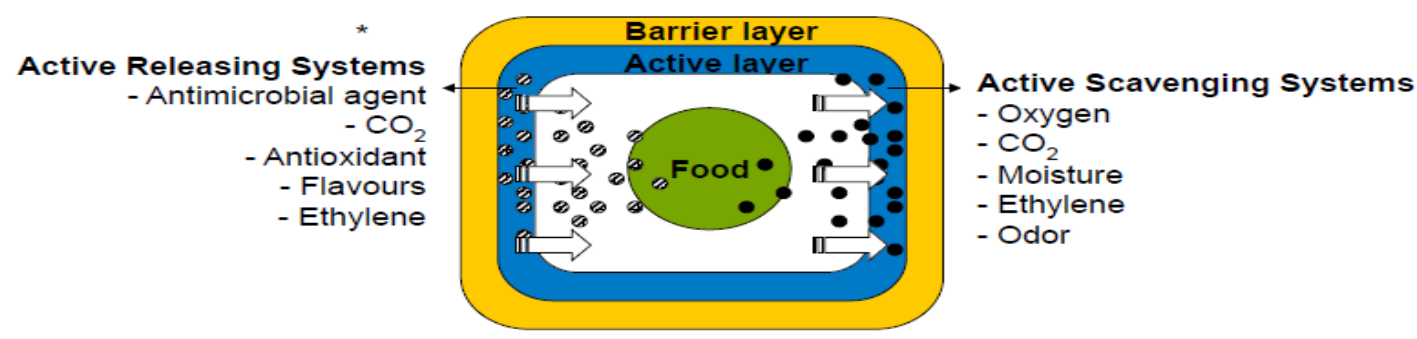

Fig. 9 - Chemical release nano-packaging barrier sytem.

(http://www.qmed.com/mpmn/gallery/image/mrsa-killing-nanoscale-coating)

In many cases, including chemical packaging release also elements of control, where the release of nano chemicals will happen in response to a trigger event. On the contrary, nano packaging using carbon nano-tubes advanced, with the ability to carbon dioxide, which would otherwise result in a food or beverage deterioration pump. Nano packaging that absorbs undesirable flavors is also in the development stage. Packaging design launch a chemical also for the release of biocides in response to the growth of microbes, humidity, or other changing circumstances (Le Good and Clarke 2006).

Packaging and other food contact materials containing nanomaterials antimicrobial, which has been designed not to be released, so that the packaging itself as an agent of antibacteria. These products are typically used nanoparticles of silver, despite the use of some Nano size zinc oxide or chlorine dioxide and other materials as shown in table (4) (Le Good and Clarke 2006 ; AzoNano 2007). Finally, for example, the use of bio-nano-fillers and plastic vital force him the benefit of generating full biological base combinations. These Nano fillers have a high surface-mass ratio, an excellent mechanical strength, flexibility, lightness and in some cases, even they are edible, since they can make from food hydrocolloids. Finally, there are still other Nano products produced in food sector. Therefore, nanotechnology technology that has been applied at all stages of the food cycle is considered.

\section{Nano-packaging and food market}

The worldwide sales of nanotechnology products in the food and beverage packaging sector increased from US \$ 150 million in 2002 to US \$ 860 million in 2004 and are expected to reach to US $\$ 20.4$ billion by 2010. It is expected Nano packaging applications as food contact materials (FCMs) to grow the business \$ 66 million in 2003, to more than \$ 360 million by 2008 . CIENTIFICA estimated consulting company, and then applications (2006) nanoparticles food in about $\$ 410$ million (\$100 million food-processing and food ingredients worth $\$ 100$ million and food packaging US $\$ 210$ million). There is great potential for the growth of the food sector in developing countries. Today, many of the world's leading food companies, including Heinz, 
Nestle, Hershey, Unilever, and Kraft are investing heavily in nanotechnology research and development. As of March 2006, more than 200 " Nano " consumer products currently available, and about $59 \%$ are classified as $9 \%$ of products such as " health and fitness " and " food and beverage, "" products, respectively. Nano science and nanotechnology and open new horizons in this century, nanotechnology food are an emerging technology (Qureshi et al. 2012).
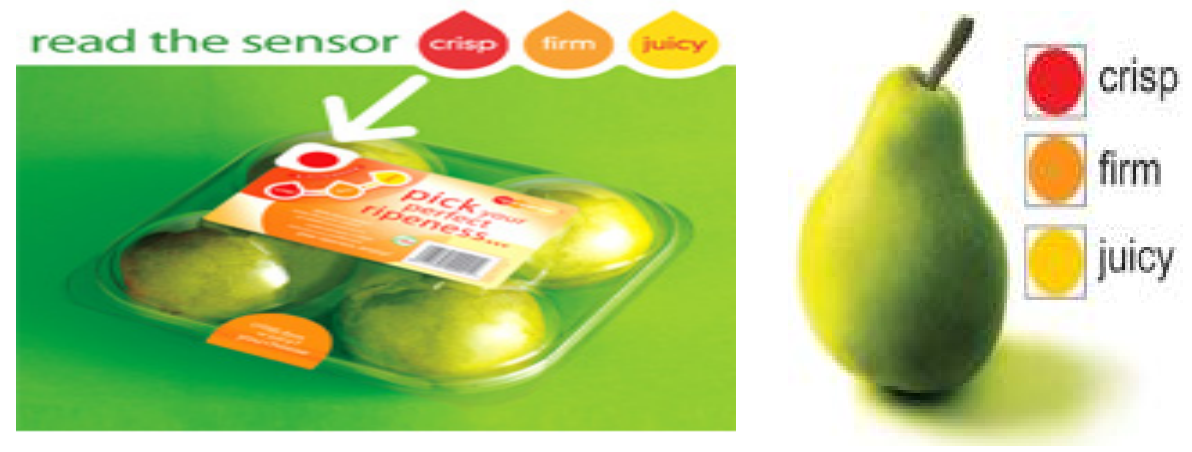

Fig. 10 - Ripe Sense ${ }^{\circledR}$ indicates the ripening of fruits. -This sensor changes color when it reacts with aromatic compounds. It reacts with aromas released by fruit as it ripens.

(https://www.google.com.eg/imgres?imgurl=http\%3A\%2F\%2Fimage.slidesharecdn.com\%2Fpreetibirwa 1-130511093543-phpapp01\%2F95\%2Fnanotechnology-in-food-packaging-

27638.jpg\%3Fcb\%3D1387445717\&imgrefurl=http\%3A\%2F\%2Fwww.slideshare.net\%2Fpreetibirwal00 7\%2Fpreetibirwal\&docid=A5oxhs51mo9n9M\&tbnid=FW9EGhv_TW8G5M\%3A\&w=638\&h=479\&ei=d 7PyVqbMMYb6aueqpagK).

Nanotechnology food is one of the emerging areas of interest and opens a whole universe of new possibilities for the food industry. In Food Engineering, it is expected two major applications for nanotechnology (any) sensing Nano nanostructured food and food ingredients. In the area of the former, it can improve food quality and safety assessment to achieve using nanotechnology. Recently "nanotechnology" is essentially a modern scientific field that is constantly evolving as a wide area of research, with regard to the dairy and food processing, preservation, packaging and the development of functional foods (Guhan et al. 2014).

Table 4 Antimicrobial food packaging based on nano-materials and their application in food sectors

\begin{tabular}{ll}
\hline Company & Applications In Food Sectors \\
\hline Song Sing NanoTechnology Co., Ltd & Cling wrap for food treated with ZnO \\
\hline $\begin{array}{l}\text { Blue Moon Goods, A-DOGlobal, Quan Zhou Hu Zheng } \\
\text { Nano Technology Co., Ltd and Sharper Image }\end{array}$ & Food storage containers treated with Ag \\
\hline Sharper Image & Plastic pags storage treated with Ag \\
\hline A-DOGlobal & Chopping boards treated with Ag \\
\hline Nanocare Technology LTD & Kitchenware treated with Ag \\
\hline Baby Dream Co., Ltd & Cup for baby treated with Ag \\
\hline Daewoo, Samsung and LG & Refrigerators treated with Ag \\
\hline Song Sing NanoTechnology Co., Ltd & Tea pots treated with Ag \\
\hline American Journal of Food Agriculture Nutrition and Development (AJFAND), Volume 10, No 6, June, 2010.
\end{tabular}

Nano food packaging materials, food may extend life, improve food and consumer safety alert that the food is contaminated or spoiled, and repair tears in the packaging, and even releasing preservatives to prolong the life of the food in the package. Nanotechnology in the food industry applications can be used for detecting bacteria in packaging, or producing stronger 
flavors and color quality, and safety by increasing the barrier properties. At the same time, nanotechnology and new materials, food technology, which requires the review of the potential negative impacts as well as many of the positive effects ? In this review, we aim to cover some of the recent developments in nanotechnology and their applicability to the food industry and packaging (Le Good and Clarke 2006 ; Guhan et al. 2014).

\section{Conclusion and future remarks}

Where he continues to developments in nanotechnology to emerge, applied to the food industry is sure to increase. The success of these developments depends on consumer acceptance and explores regulatory issues. Food manufacturers and producers to make great strides in the field of food safety by using nanotechnology, and consumers can reap the benefits as well. More and more companies are conducting research in nano-technology and its application to food products, as most of its functions became clear, that the level of interest is sure to increase.

In addition to scientific and technical progress necessary to continue the application of nanotechnology to food technology, and organizational considerations (including the safety / toxicology and environmental impact), the economy and consumer acceptance of nanotechnology dictate the ultimate success in food applications.

Agricultural producers and food manufacturers can earn more competitive through the application of nanotechnology position, and in the long term, the consumer may benefit from advances in nanotechnology that contribute to the agricultural and food local system competitive and innovative, and provide new ways to improve food safety of food products and value. In short, we can recommend that there is an urgent need to regulate nanomaterials before they are incorporated in the food industry and packaging, and food contact.

Nanomaterials supposed to be not cause any health risks to consumers or the environment and therefore there is an urgent need for more research studies to investigate the risks of nanomaterials bearing in mind that is some chemicals in the form of large particles are safer than it were in the Nano form.

\section{References}

Antonio J. R., Antônio C. R., Cardeal I. L. S, Ballavenut J. M. A. and Oliveira J. R. 2014. Nanotechnology in dermatology. Anais Brasileiros De Dermatologia 89(1): 126-136.

Arora A. and Padua G.W. 2010. Review: nanocomposites in food packaging. J. Food Sci. 75:4349.

AzoNano. 2007. Advanced nanotechnology gets grant for food packaging. Nanotechnology News Archive. Available at: http://www.azonano.com/news.asp?newsID=3177.

Berekaa M. M. 2015. Review Article; nanotechnology in food industry; advances in food processing, packaging and food safety. Int. J. Curr. Microbiol. App. Sci. 4(5): 345-357.

Brody A. L. 2006. Nano and food packaging technologies converge. Food Technol. 60: 92-94.

Brunner T., Piusmanser P., Spohn P., Grass R., Limbach L., Ruinink A. B. and Stark W. 2006. In vitro cytotoxicity of oxide nanoparticles: Comparison to asbestos, silica, and the effect of particle solubility. Environ. Sci. Technol. 40:4374-4381.

Cha D. and Chinnan M. 2004. Biopolymerbased antimicrobial packaging: A review. Crit. Rev. Food Sci. Nutr. 44: 237-237.

Chaudhry Q., Scotter M., Blackburn J., Ross B., Boxall A., Castle L., Aitken R. and Watkins R. 2008. Applications and implications of nanotechnologies for the food sector. Food Additives and Contaminants 25(3): 241-258.

Chen M. and Mikecz A. 2005. Formation of nucleoplasmic protein aggregates impairs nuclear function in response to $\mathrm{SiO}_{2}$ nanoparticles. Experiment Cell. Res. 305:51-62.

Ding Y. and Povey M. 2005. Nanotech discovery promises safer food packaging. http;// www.foodprductiondaily.com/news/ng.asp?n=59980-discovery-pro. 
Duncan T. V. 2011. Applications of nanotechnology in food packaging and food safety: Barrier materials, antimicrobials and sensors. J. Colloid. Interface. Sci. 363(1): 1-24.

EFSA - European Food Safety Authority. 2009. The potential risks arising from nanoscience and nanotechnologies on food and feed safety (EFSA-Q-2007-124a). The EFSA Journal 958,139.http://www.efsa.europa.eu/EFSA/efsa_locale1178620753812_1211902361968.h tml.

El Amin A. 2005. Consumers and regulators push food-packaging innovations. http;// www.foodproductiondaily.com/news/ng.asp?n=63704-frost-and-sullivanmap.

El Amin A. 2006. Nano ink indicates safety breach in food packaging. FoodNavigator.com 14 November 2006. Available at: http://www.foodnavigator.com/news/ng.asp?id=7202 2.

El Amin A. 2007a. Nanoscale particles designed to block UV light. FoodProductionDaily.com Europe. 18 October (2007). Available at: http://foodproductiondaily.com/news/ng.asp?id.

El Amin A. 2007b. Nano scale coating process developed for baking sector. Food Production Daily 28 February 2007. Available at: http://www.foodproductiondaily.com/news/ng.asp?id=74584.

Elmasry S. A., Elgawish M. A., El-Shawy O. E., Askar M. A., Helmy E. A. and Rashed L. A. 2016. Biologically synthesized Quercetin loaded magnetite nanoparticles enhanced cytotoxicity and radiosensitivity of cancer cells in Vitro. Journal of Chemical and Pharmaceutical Research 8(8):758-771.

Food and Agriculture Organization of the United Nations/World Health Organization, FAO/WHO (2009). FAO/WHO Expert meeting on the application of nanotechnologies in the food and agricul-ture sectors: Potential food safety implications: Meeting Report. Rome.

Food Safety Authority of Ireland, (2009). Leaflet: Nanotechnology and food. Available at www.fsai.ie/Nanotechnology leaflet.

Goffin A. L., Raquez J. M., Duquesne E., Siqueira G., Hbibi Y., Dufresne A. and Dubois P. 2011. From interfacial ring-opening polymerization to melt processing of cellulose nanowhisker-filled polylactide-based nanocomposites. Biomacromolecules 12(7): 24562465.

Gokila T. and Thiruvengadam S.1. 2014. Nanotechnology in food industry - A review. Int.J. ChemTech Res. 6(9): 4096-4101.

Gouin S. 2004. Micro-encapsulation: Industrial appraisal of existing technologies and trends, Trends in Food Sci. and Tech. 15: 330-347.

Guhan N. S. and Sam A. I. 2014. Recent Innovations in Nanotechnology in Food Processing and its Various Applications - A Review. Int. J. Pharm. Sci. Rev. Res. 29 (22): 116-124.

Francisco J., Gutie R., Ma Luisa M., Paloma G. and Ruth R. (2012). Nanotechnology and Food Industry, Scientific, Health and Social Aspects of the Food Industry, Dr. Benjamin Valdez (Ed.), ISBN: 978-953-307-916-5, InTech, Available from: http://www.intechopen.com/books/scientific-health-and-socialaspects-of-the-foodindustry/nanotechnology-and-food-industry, pp. 96-128.

Heinlaan M., Ivask A., Blinova I., Dubourguier H. and Kahru A. 2008. Toxicity of nanosized and bulk $\mathrm{ZnO}, \mathrm{CuO}$ and $\mathrm{TiO} 2$ to bacteria Vibrio fischeri and crustaceans Daphnia magna and Thamnocephalus platyurus. Chemosphere 71: 1308-1316.

Helmy E. A. 2015. Biogenesis of radiolytic silver nanoparticles via Aspergillus oryzae and their antimicrobial impact. Egyptian Journal of Biotechnology 48: 135-155.

Helmy E. A. and Mekawey A. A. 2013. Mycobiosynthesis, optimization and characterization of silver nanoparticles. The African Journal of Mycology and Biotechnology 18 (2): 57-77.

Helmy E. A. and Mekawey A. A. 2014. Envision of the microbial contact with Mycosynthesized silver nanoparticles. Research Journal of Pharmaceutical, Biological and Chemical Sciences 5(5):344-359. 
LaCoste A., Schaich K., Zumbrunnen D. and Yam K. 2005. Advanced controlled release packaging through smart blending. Packag. Technol. Sci. 18: 77-87.

Lagarón J. M. and Lopez-Rubio A. 2011. Nanotechnology for bioplastics: opportunities, challenges and strategies. Trends in Food Science \& Technology, doi: 10.1016/j.tifs.2011.01.007.

Lagarón J. M., Cabedo L., Cava D., Feijoo J. L., Gavara R and Gimenez E. 2005. Improving packaged food quality and safety. Part 2: Nanocomposites. Food Additiv. Contam. 22: 994-998.

Launois A. 2008. Nanoparticles could improve food safety. http;//www.meatprocess.com/news/ng.asp? =84601-nanotechnology

Lepot N.m Van Bael M. K., Van den Rul H., D’Haen J., Peeters R., Franco D. and Mullens J. 2011. Influence of incorporation of $\mathrm{ZnO}$ nanoparticles and biaxial orientation on mechanical and oxygen barrier properties of polypropylene films for food packaging appliations. Journal of Applied Polymer Science 120(3): 1616-1623.

Li X. H.; Xing Y. G., Li W. L., Jiang J. H. and Ding Y. L. 2010. Antibacterial and physical properties of poly (vinylchoride)-based film coated with $\mathrm{ZnO}$ nanoparticles. Food Science and Technology International 16(3): 1082-0132.

Long T. N., Saleh R., Tilton R., Lowry G. and Veronesi B. 2006. Titanium dioxide (P25) produces reactive oxygen species in immortalized brain microglia (BV2): Implications for nanoparticle neurotoxicity. Environ. Sci. Technol. 40(14): 4346-4352.

Mills A. and Hazafy D. 2009. Nanocrystalline SnO2-based, UVB-activated, colourimetric oxygen indicator. Sensors and Actuators B-Chemical 136 (2): 344-349.

Morones J.R., Elechiguerra J. L., Camacho A., Holt K., Kouri J. B., Ramirez J. T. and Yacaman M. J. 2005. The bactericidal effect of silver nanoparticles. Nanotechnology 16(10): 23460-353.

Oberdörster G., Oberdörster E., and Oberdörster J., 2005. Nanotoxicology: An emerging discipline evolving from studies of ultrafine particles. Environmental Health Perspectives, 113 (7): 823-839.

Qureshi M. A., Karthikeyan S., Punita K., Khan P. A., Uprit S. and Mishra U. K. 2012. Application of nanotechnology in food and dairy processing: An overview. Pak. J. Food Sci. 22(1): 23-31.

Renton A. 2006. Welcome to the world of nanofoods. Guardian Unlimited UK 13 December. Available at: http://observer.guardian.co.uk/foodmonthly/futureoffood/story/0,,1971266,00.html.

Reynolds G. 2007. FDA recommends nanotechnology research, but not labelling.FoodProductionDaily.com News 26 July 2007. Available at http://www.foodproductiondaily-usa.com/news/ng.asp?n=78574woodrowwilsonnanotechnologyhazardous.

Shefer A. and Shefer S. 2003. Biodegradable bioadhesive controlled release system of nanoparticles for food products, U.S. patent; 6565873BI.

Silvestre C., Duraccio D. and Cimmino S. 2011. Food packaging based on polymer nanomaterials. Progress in Polymer Science 36: 1766-1782.

Sintef T. J. 2004. Space station technology applied to food packaging. http;//www.foodproductiondaily.com/news/ng. aspn=54940-space-stationtechnology.

Slnchez-Garcya M. D., Lagaron J. M. and Hoa S. V. 2010a. Effect of addition of carbon nanofibers and carbon nanotubes on properties of thermoplastic biopolymers. Composites Science and Technology, 70, (7): 1095-1105.

Slnchez-Garcya, M. D.; Lopez-Rubio, A. and Lagaron, J. M. 2010b. Natural micro and nanobiocomposites with enhanced barrier properties and novel functionalities for food biopackaging applications. Trends in Food Science \& Technology 21: 528-536. 
Sorrentino A., Gorrasi G. and Vittoria V. 2007. Potential perspectives of bionanocomposites for food packaging applications. Trends Food Sci Technol 18:84-95.

Sundararajan B. and Ranjitha B. D. 2014. Biosynthesis of silver nanoparticles in Lagerstroemia speciosa (1.) Pers and their antimicrobial activities. International Journal of Pharmacy and Pharmaceutical Sciences 6 (3): 30-34.

Suppakul P., Miltz J., Sonneveld K. and Bigger S. W. 2003. Active packaging technologies with an emphasis on antimicrobial packaging and its applications. Journal of Food Science 68 (2): 408-420.

Troncarelli M. Z., Brandão H. M., Gern J. C., Guimarães A. S., Langoni H. 2013.Nanotechnology and antimicrobials in veterinary medicine. Formatex 13:543-556.

Uricanu V. I., Duits M. H. G. and Mellema J. 2004. Hierarchical networks of casein proteins: An elasticity study based on atomic force microscopy. Langmuir 20: 5079-5090.

Valdiglesias V., Costa C., Sharma C., Kilic G., Pasaro E., Teixeira J. P., Dhawan A. and Laffon B. 2013. Comparative study on effects of two different types of titanium dioxide nanoparticles on human neuronal cells. Food Chem. Toxicol. 57: 352-361.

Vladimiriov V., Betchev C., Vassiliou A., Papageorgiou G. and Bikiaris D. 2006. Dynamic mechanical and morphological studies of isotactic polypropylene /fumed silica nanocomposites with enhanced gas barrier properties. Composites Science and Technology 66: 2935-2944.

Wang B., Feng W. W., Wang M., Wang T., Gu Y., Zhu M., Ouyang H., Shi J., Zhang F., Zhao Y., Chai Z., Wang H. and Wang J. 2007. A cute toxicological impact of nano- and submicro-scaled zinc oxide powder on healthy adult mice. J. Nanopart. Res. 10 (2):263276.

Yang H. L., Lin J. C. and Huang C. 2009. Application of nanosilver surface modification to RO membrane and spacer for mitigating biofouling in seawater desalination. Water Research 43: 3777-3786.

Yu H. L. and Huang Q. R. 2010. Enhanced in vitro anti-cancer activity of curcumin encapsulated in hydrophobically modified starch. Food Chem. 119: 669-674.

Zhu K., Dietrich R., Didier A., Doyscher D. and Märtlbauer E. 2014. Recent developments in antibody-based assays for the detection of bacterial toxins. Toxins 6: 1325-1348. 